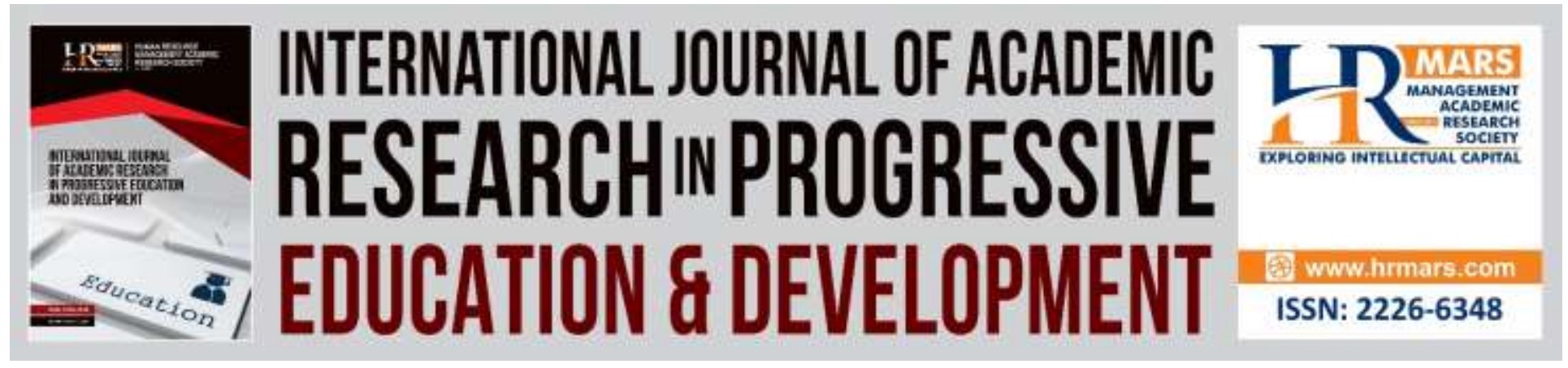

\title{
Effects of Cognitive Therapy Intervention (CTI) on the Resilience with Problematic Behavior Among the Adolescents
}

Nasir Len, Amalia Madihie \& Salmah Mohamad Yusoff

To Link this Article: http://dx.doi.org/10.6007/IJARPED/v9-i2/7301

DOI:10.6007/IJARPED/v9-i2/7301

Received: 18 March 2020, Revised: 20 April 2020, Accepted: 17 May 2020

Published Online: 04 June 2020

In-Text Citation: (Len et al., 2020)

To Cite this Article: Len, N., Madihie, A., \& Yusoff, S. M. (2020). Effects of Cognitive Therapy Intervention (CTI) on the Resilience with Problematic Behavior Among the Adolescents. International Journal of Academic Research in Progressive Education and Development, 9(2), 276-288.

Copyright: (C) 2020 The Author(s)

Published by Human Resource Management Academic Research Society (www.hrmars.com)

This article is published under the Creative Commons Attribution (CC BY 4.0) license. Anyone may reproduce, distribute, translate and create derivative works of this article (for both commercial and non-commercial purposes), subject to full attribution to the original publication and authors. The full terms of this license may be seen

at: http://creativecommons.org/licences/by/4.0/legalcode

Vol. 9(2) 2020, Pg. 276 - 288

http://hrmars.com/index.php/pages/detail/IJARPED

JOURNAL HOMEPAGE

Full Terms \& Conditions of access and use can be found at http://hrmars.com/index.php/pages/detail/publication-ethics 


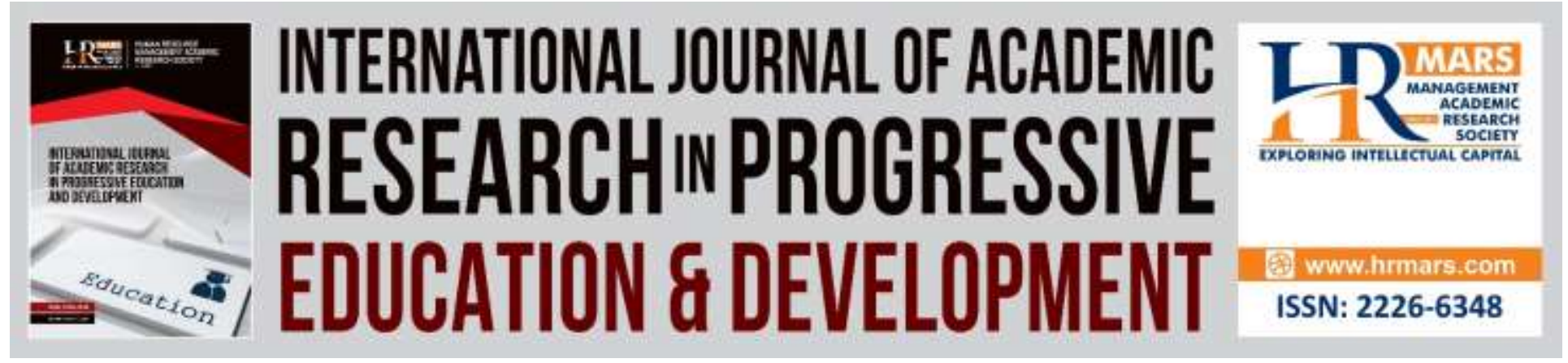

\title{
Effects of Cognitive Therapy Intervention (CTI) on the Resilience with Problematic Behavior Among the Adolescents
}

\author{
Nasir Len ${ }^{1}$, Amalia Madihie ${ }^{2}$ \& Salmah Mohamad Yusoff ${ }^{3}$ \\ Counselling Programme, Faculty of Cognitive Sciences and Human Development \\ Universiti Malaysia Sarawak, Kota Samarahan, Sarawak, Malaysia. \\ Email: nasslen@yahoo.com¹, mamalia@unimas.my²,mysalmah@unimas.my ${ }^{3}$
}

\begin{abstract}
Behavioral problems among adolescents are still widespread today, especially among the school students. Although the issue is widespread, an experimental study that focuses on the intensity of the problematic adolescents is still lacking in this country. To address these symptoms, the purpose of this experimental study is to look at the effects of the Cognitive Therapy Intervention (CTI) Module on resilience of adolescents' with problematic behaviour. This study was conducted on 60 form four students. Students were divided into two groups which are treatment group $(n=30)$ and control group $(n=30)$. The treatment group was given intervention using the CTI module while the control group did not receive any intervention throughout the period of the experimental study. To control the differences of dependent variables, pre-test was given before treatment started. After eight weeks of treatment, the two groups were given a post-test followed by retention tests a month later. The questionnaire used to obtain the study data was based on Resilience Scale. Data analysis was created using the SPSS-Windows version 25.0 program. The data was analyzed using Analysis of Split Anova (SPANOVA). The results of the study found that CTI interventions succeeded in enhancing the survival of adolescent with problematic behaviors. It is proposed that CTI can be carried out as an alternative method of treating non-behavioural adolescents. Implication to the body of knowledge is expected to help the counsellors, educators and schools to improve students' resilience and thereby reducing the behavioural problems among school students.

Keywords: Effectiveness, Cognitive Therapy Intervention, Resilience, Adolescents, Behaviour Problem
\end{abstract}

\section{Introduction}

Studies showed that behavioural problem issues need to be given serious attention due to the increasing number of adolescents' involvement with various behavioural problems. Keywords used to describe problematic behaviour among the adolescents are inner and outer 
behavioural problem, substance abuse, delinquent, academic failure, antisocial and risky sexual behaviour (Sun \& Shek, 2013). The main risky factors contributing to behavioural problems are family issuess, school adaptiveness issues, psychological adaptiveness issues and negative peer relationship (Milkman \& Wanberg, 2012).

Jessor (1998) stated that adolescents' problematic behaviour is the product of the interaction of three systems namely personality system, environmental response and behaviour system. Adolescents are said to be problematic when their personality systems experience particular traits such as low self-appreciation, low expectation towards success, isolation and lost of hopes. Environmental response can be described as the parents' unsupportive acts, antisocial peer influences and problematic behaviour role model while behaviour system happens when there is no relationship with the convensional institution and the lesser feeling of accomplishment in school. Research findings supported this theory and the factors contributing to the behavioural problems are unhealthy relationship between the adolescents and their parents, negative life experience, study pressure, the feeling of less sense of belonging in school and passive coping actions (Chang et al., 2013; Wang, Liu, \& Wang, 2014), adolescents' family traits, neighbourhood supports and their acculturation (White \& Renk, 2011). Thus, adolescents need the element of resilience which has become their proctective factors such as good relationship with the adults, having supportive family, outer normative control perception, positive peer model, good grades in school, the involvement in pro-social groups and beneficial social activities, positive attitude towards school, non-tolerance to deviant behaviour, having strong religious beliefs and taking part in volunteer activities.

Resilliency is an important mechanisme to oneself because a resilient person can easily adapt to the painful life experience. Resiliency also seen as the protector to overcome psychological disorder by a positive adaptation to the stressful life (Loh et al., 2014). Wagnild dan Young (1993) defined resiliency as a resistance personality trait that consists of five interrelated components including life goals, equanimity, preserverence, self-reliance and authenticity. Life goals inspire life, equaminity is a balance in life, preserverence refers to determination to continue the struggle against adversity, self-reliance means having confidence in the ability of oneself and authenticity reflects the awareness that each individual has a unique way of life.

The implementation of strict disciplinary action against students has been found to be ineffective in handling adolescent behavioural problems in school. For example, school suspension only gives a slight positive impact, but the students' behaviour repeats again. Corporal punishment can cause physical, emotional and psychological injury and it is estimated that 1 to 2 percent of students who have had whipping sentence experience school traumatic symptoms (Cameron, 2006). Meta-analysis studies conducted from the year 1986 to 2012 on 53 cases from 34 studies showed there was a negative relationship between suspension punishment and academic achievement but a positive relationship with the student dropouts are found (Noltemeyer, Ward, \& Mcloughlin, 2015). So, counselling intervension is the most suitable alternative to overcome behavioural problems among school students. Treatment that uses counselling and psychotherapy intervention approach are found to be effective in modifying problematic behaviour among school students in the age group of 6 to 17 years old (Erford, Paul, Oncken, Kress, \& Erford, 2014). 
Conceptually, adolescents' problematic behaviour rose from distorted thinking because feelings and behaviour are not caused by the environment or events but are caused by the way adolescent make an environmental response and interpretations of events that occur on them (Squires \& Caddick, 2012). Negative thinking pattern cause adolescents to have no resistance to psychological problems due to painful events and environmental conditions. The formation of distorted thinking in adolescents with behavioural problems is through their process of life covering personal and contextual factors. Personal factors include genetics, personality, physical inability, learning problems, mobility skills, social skills, self-esteem, intelligence and value systems. Contextual factors include the level of upbringing and parenting, family relationships, experiences and achievements in school, neighbourhood, loss, abuse, bullying and social isolation (Simmons \& Griffiths, 2009). Intervention of Cognitive Therapy has effectively reduced the level of anxiety and improved the ability to control anger among adolescents (Karahan, Yalcin, \& Erbas, 2015), improving positive thinking and strategies of action and reducing the symptoms of anxiety (Hogendoorn, Prins, Garst, Hartman, \& Haan, 2014), reduced antisocial behavior and emotional stress but did not improve positive self (Cone, Golden, \& Hall, 2009). Cognitive Therapy has been successful in treating various problems ranging from depression, anxiety disorders to chronic illness, but there is still a lack of aspects of the development of quality and positive qualities in individuals (Padesky \& Mooney, 2012).

Hence, in order to make Cognitive Therapy more comprehensive then it needs to be combined with a constructive endurance to help adolescents face resistance in their environment and painful life events. Resilience is a process that allows a person to act and adapt to the stress of life. There are many advantages of resillience to oneself, including making someone more confronting with their obstacles and also accepting something that can not be changed. With this, it becomes a buffer to protect someone in terms of psychology and physical health over time. The fact is that durability is required, but some individuals have never built resilience while others fail to identify endurance (Padesky and Mooney, 2012).

\section{The Cognitive Therapy Intervention (CTI) Framework in the Context of Problematic Behaviour Adolescents}

Adolescents who have an automatic negative thought such as school is time-consuming and there is no hope of passing, are unaware of the thought. Therefore, this thought needs to be identified and restructured through mind challenging technique, seeking proof of the thought and problem solving and then instilled elements of resistance and self-reliance. Emotional problems such as anger, sadness, guilt and fear are treated using negative beliefs analysing technique followed by incorporating the authenticity resistance. Physical sensations such as increased heartbeat or short breathing are the effects from emotional treatment by providing relaxation exercises, managing negative emotions and evaluating distorted thoughts and putting in great equaminity resistance. While problematic behaviors such as truancy, smoking, disobedience and quarrels are treated with alternative building techniques and personal scheme modifications and implanted resillience of living goals.

Based on cognitive therapy, the element of stress in thought, feeling and behavior is interconnected with each other. The changes in one of these elements will result in changes to 
INTERNATIONAL JOURNAL OF ACADEMIC RESEARCH IN PROGRESSIVE EDUCATION AND DEVELOPMENT

Vol. 9, No. 2, 2020, E-ISSN: 2226-6348 @ 2020 HRMARS

the other elements. In the context of these troubled adolescents, a negative change in one element will start a bad cycle that will impact other elements of psychological stress.

\begin{tabular}{|l|l|}
\hline $\begin{array}{l}\text { Cognitive } \\
\text { Intervention }\end{array}$ & Resilience \\
\hline $\begin{array}{l}\text { - Finding negative } \\
\text { thinking evidence. } \\
\text {-problem solving. } \\
\text {-challenging } \\
\text { thinking }\end{array}$ & Perseverence \\
& \\
\hline
\end{tabular}

Thinking

(School is a waste of time and there is no hope to pass)

Behavorial effect
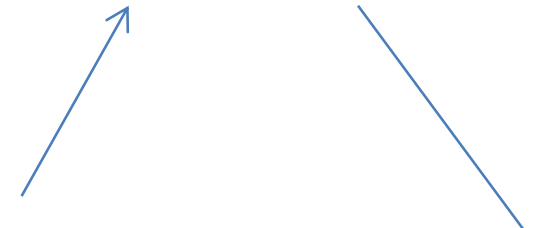

\begin{tabular}{|l|l|}
\hline $\begin{array}{l}\text { Emotional } \\
\text { intervention }\end{array}$ & Resilience \\
\hline $\begin{array}{l}\text { Analysis } \\
\text { Negative belief }\end{array}$ & Authenticity \\
\hline
\end{tabular}

(perfoymance declined, feeling lazy to wake up in the morning )

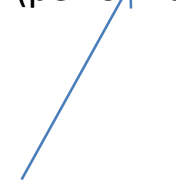

Behavorial

(escape, smoking, talk back)

feelings (emotionaly-angry, hate,guilty)

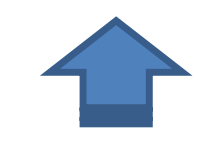

\begin{tabular}{|l|l|}
\hline Behavorial intervention & Resilience \\
\hline -building an alternative & Purpose \\
scheme for self- & \\
changing. & \\
-Positive formation & \\
\hline
\end{tabular}

feelings (phisically-tired, tense muscles)

\begin{tabular}{|l|l|}
\hline Phisical & Resilience \\
intervention & \\
\hline -Relaxing practice. & Equanimity \\
-Managing & \\
negative emotion & \\
-assesing distorted & \\
thinking. & \\
\hline
\end{tabular}


INTERNATIONAL JOURNAL OF ACADEMIC RESEARCH IN PROGRESSIVE EDUCATION AND

DEVELOPMENT

Vol. 9, No. 2, 2020, E-ISSN: 2226-6348 @ 2020 HRMARS

Figure 1. Cognitive Therapy Intervention and adolescents with behavorial problems resilience conceptual framework.

Hence, the objective of this study is to assess the effects of Cognitive Therapy Interventions (CTI) by measuring the difference between the mean readings, post-test and follow-up tests of behaviour-resistant adolescent's resistance versus variables.

\section{Methodology}

\section{Research Sample}

Research sample was chosen randomly based on two phases. The first phase was according to suggestions from teachers, disciplinary teacher, administrator and also based on the record from Merit and Demerit System guided by disciplinary misconduct cases in Sistem Salah Laku Disiplin Murid (SSDM 2016) Ministry of Education Malaysia such as criminal behavior, drugs/inhalants/toxins abuse, bullying, skipping schools, smoking, obscene behavior, impolite behavior, vandalism, untrustworthy behavior, mischievous, time ignorance behavior, personal hygiene and political involvement. During the second phases, the chosen sample went through a sorting process to separate the sample from psychological aspect by using Resilience Scale (RS) Malay language version translated by Madihie, Noah, Baba and Jaafar (2011). Sample with higher RS score compare to mean score is taken out from intervention list. Sample with average RS score compare to mean score is maintained in the intervention list which is known as research sample. There were thirty samples fulfilled the inclusion criteria on the study.

Pretest data was conducted one week before the real treatment. After the score in Resilience Scale was obtained, sixty subjects with average mean score was chosen as the sample of experiment. Samples were assigned randomly into two groups through pair random sampling which are treatment group and control group. Thirty subjects in treatment group received eight sessions of Cognitive Intervention Therapy (CTI) for eight weeks, while subjects in control group did not receive any treatment during the treatment weeks. However, the control group would receive the CTI after the experiment. Post-test data was taken at eighth CTI sessions for treatment group and control group. After a month, data for retention test was taken from both treatment and control group. Descriptive data was analysed and interpreted by using mean score and standard deviation using one way ANOVA test, SPANOVA test, Bonferroni test, Mauchly's Sphericity test and Levene's test.

\section{Research Instruments}

The study has employed two research instruments: The Resilience Scale and the Cognitive Therapy Intervention. Below is the details of the instruments:

a) Resilience Scale

In this research, researcher employed Resilience Scale (RS) by Amalia Madihie et al. (2011) to measure resilience characteristics of adolescents with behavorial problems. The scale has 25 items and responds from this questionnaire is based on seven choices 1-7 positive items that represent 5 sub-scale. The items are as in the following table: 
Vol. 9, No. 2, 2020, E-ISSN: 2226-6348@ 2020 HRMARS

\section{Table 1}

Resilience Scale (RS) Sub Scale

\begin{tabular}{|c|c|c|}
\hline Sub scale & & Items \\
\hline Reliance & (SR) & $2,9,13,18$ dan \\
\hline Meanings (M) & & $4,6,11,15$ dan 21 \\
\hline Equanimity & $E$ & $7,12,16,19$ dan 22 \\
\hline Perseverance & $(P)$ & $1,10,14,20$ dan 24 \\
\hline Authenticity $(A)$ & & $3,5,8,17$ dan 25 \\
\hline
\end{tabular}

\section{Cognitive Therapy Intervention}

In this research, researchers designed a counselling module based on module building procedure which has been introduced by Russell (1974) and Sidek (2011). Cognitive Therapy Intervention (CTI) is based on Cognitive Model introduced by Beck 1976 illustrating on how emotional problems are caused by negative thinking and proven that the problems can be reduced by changing the pattern of thinking. CTI module has eight activity sessions which are group introduction and building relationship, cognitive formulation, meanings resilient, perseverance resilient, equanimity resilient, self-acceptance resilient, authenticity resilient and group termination session. According to Sidek Mohd Noh \& Jamaluddin (2005) it is shown that 70 percent achievement is considered a high achievement. This has been supported by Abu Bakar Nordin (1995) whereby the value of reliability of CTI module is 0.83 while the validity value is 0.86 . This shows that the reliability and validity value of this module are very high and acceptable with Hopkins ideas (1998).

\subsection{Findings}

Result of Box's M test shows that data is compatible towards covariant equality requirements of MANOVA test (Chua, 2011). Results of Box's M test in Table 2 shows a significant results of $[p=0.177, p>0.05]$. Therefore, ANOVA analysis can be continued.

\section{Table 2}

Covariant Equality test

\begin{tabular}{lcc}
\hline Box's Test of Equality of Covariance Matrices $^{\mathrm{a}}$ & \\
\hline Box's M & 9.471 & \\
F & 1.490 & \\
df1 & 6 & 24373.132 \\
df2 & & \\
Sig. & .177 & \\
\hline
\end{tabular}

* Significant at $p>.005$

Table above shows the value of Box test that is insignificant, showing that covariant dependent variables towards groups of independent variables are the same. This shows that the equality of the SPANOVA test covariance value is adhered 
INTERNATIONAL JOURNAL OF ACADEMIC RESEARCH IN PROGRESSIVE EDUCATION AND

DEVELOPMENT

Vol. 9, No. 2, 2020, E-ISSN: 2226-6348 @ 2020 HRMARS

Table 3

Levene's Test

Levene's Test of Equality of Error Variances ${ }^{a}$

\begin{tabular}{lllll}
\hline & $\begin{array}{l}\text { Levene } \\
\text { Statistic }\end{array}$ & df1 & df2 & Sig. \\
\hline $\begin{array}{l}\text { Pretest Resilient Score } \\
\begin{array}{l}\text { Post-test Resilient Score } \\
\text { Retention test Resilient Score }\end{array}\end{array}$ & .329 & 1 & 58 & .568 \\
& .838 & 1 & 58 & .364 \\
\hline
\end{tabular}

Table 3 above shows Levene test result that is insignificant for dependent variables in the research population are equal for both respondent groups of research. Thus, the research data fulfilled the similarity of SPANOVA test variance.

The research is done to observe the effects of Cognitive Therapy Intervention (CTI) towards adolescents with behavorial problems. The effects of Cognitive Therapy Intervention (CTI) are studied by observing the differences between the mean score of subjects resilient which is adolescents with behavorial problems. Table 2 is the result obtained from two way ANOVA test for free samples which shows that mean score for both treatment group and control group are different significantly $[\mathrm{F} 1,58)=938.7, p<.05]$. This shows that Cognitive Therapy Intervention (CTI) is able to increase subject with behavorial problems resiliency in treatment group compare to the one in control group.

Table 4

Tests of Between-Subjects Effects

Measure: MEASURE_1

Transformed Variable: Average

\begin{tabular}{lllllll}
\hline & Type III Sum & & & Partial & Eta \\
Source & of Squares & df & Mean Square & S & Sig. & Squared \\
\hline Intercept & 2618467.222 & 1 & 2618467.222 & 32389.417 & $\mathbf{. 0 0 0}$ & .998 \\
Group & 75891.200 & 1 & 75891.200 & 938.745 & .000 & .942 \\
Error & 4688.911 & 58 & 80.843 & & & \\
\hline
\end{tabular}

Table 4 below shows the test result after $\mathrm{df}$ value adjustment by using Huyhn-Feldt value to show the main effect of variable in the test $[F(1.71,99.30)=15.90, p<.05]$ and group test interaction effect $[F(1.71,99.30)=292.27, p<.05]$ that is significant. This shows that CTI does not only affect the adolescents with behavorial problems resilient individually but also in group interactions. 
INTERNATIONAL JOURNAL OF ACADEMIC RESEARCH IN PROGRESSIVE EDUCATION AND DEVELOPMENT

Vol. 9, No. 2, 2020, E-ISSN: 2226-6348@ 2020 HRMARS

\section{Table 5}

Test of Within-Subjects Effects

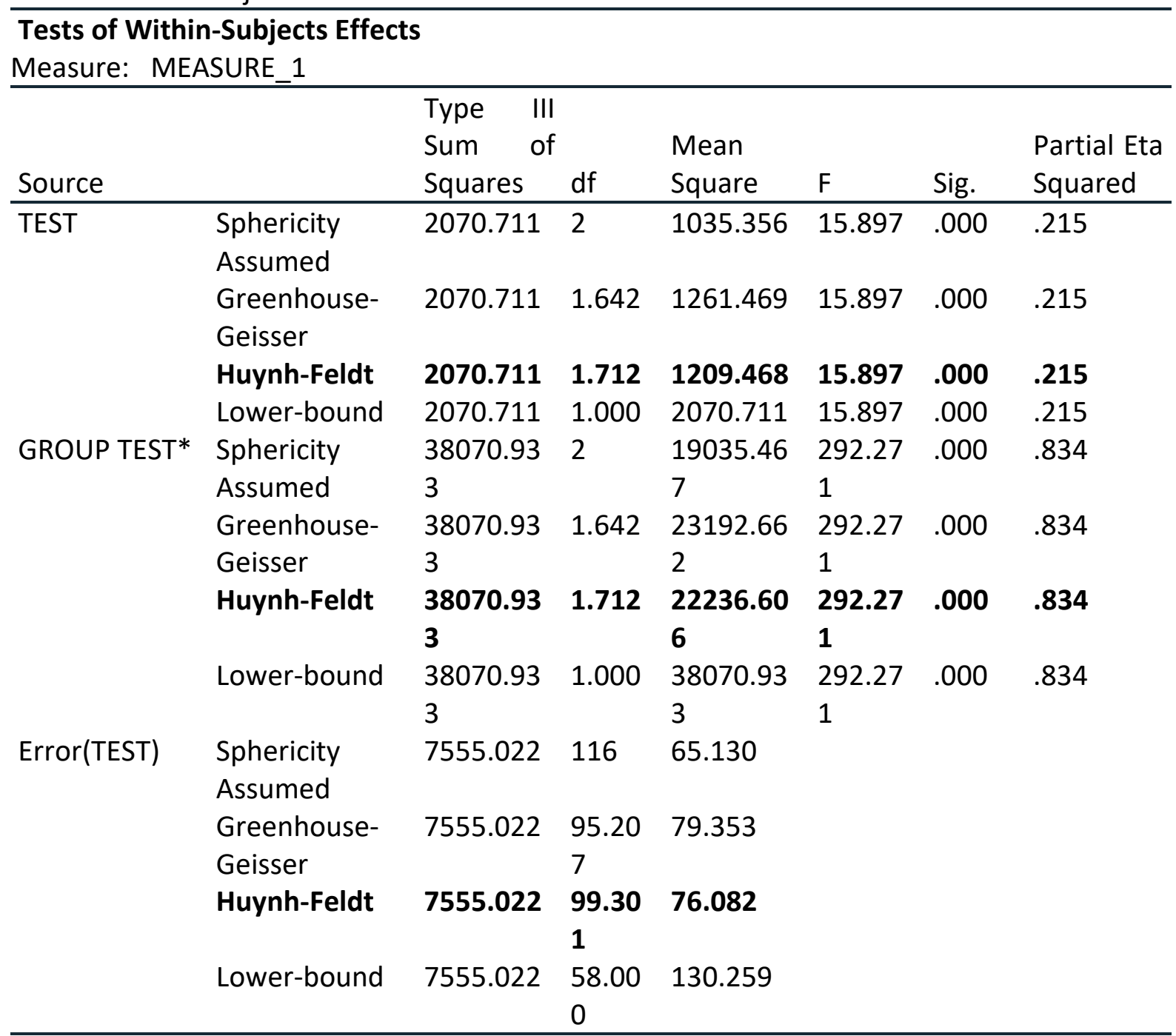

Besides that, the pair comparison test in Table 5 shows that after controlling 1 type error by using Bonferroni Method, resilient score for post-test had surpassed the pretest score significantly (difference in resilient score for post-test - pretest $=8.30, p<.05$ ). Value of score for retention test has also surpassed the pretest score significantly (difference in retention test resilient score - pretest $=3.83, p<.05)$. This result shows that significantly, there is an increase in the value of mean score for resiliency post-test and retention test compared to pretest. 
DEVELOPMENT

Vol. 9, No. 2, 2020, E-ISSN: 2226-6348@ 2020 HRMARS

Table 6

Pairwaise Comparison

Pairwise Comparisons

Measure: MEASURE_1

\begin{tabular}{|c|c|c|c|c|c|c|}
\hline \multirow[b]{2}{*}{ (I) UJIAN } & \multirow[b]{2}{*}{ (J) UJIAN } & \multicolumn{3}{|l|}{ Mean } & \multicolumn{2}{|c|}{$\begin{array}{l}\text { 95\% Confidence Interval for } \\
\text { Difference }^{b}\end{array}$} \\
\hline & & Difference (I-J) & Std. Error & Sig. ${ }^{b}$ & Lower Bound & Upper Bound \\
\hline \multirow[t]{2}{*}{1} & 2 & $-8.300^{*}$ & 1.384 & .000 & -11.711 & -4.889 \\
\hline & 3 & $-3.833^{*}$ & 1.204 & .007 & -6.801 & -.865 \\
\hline \multirow[t]{2}{*}{2} & 1 & $8.300^{*}$ & 1.384 & .000 & 4.889 & 11.711 \\
\hline & 3 & $4.467^{*}$ & 1.775 & .044 & .091 & 8.842 \\
\hline \multirow[t]{2}{*}{3} & 1 & $3.833^{*}$ & 1.204 & .007 & .865 & 6.801 \\
\hline & 2 & $-4.467^{*}$ & 1.775 & .044 & -8.842 & -.091 \\
\hline
\end{tabular}

Based on estimated marginal means

*. The mean difference is significant at the .05 level.

b. Adjustment for multiple comparisons: Bonferroni.

Table 6 above shows the result of pairwise comparison test for resilient score between test, which shows that every comparisons are significant $(p<.05$, after type error $I$ is controled by using Bonferroni).

\section{Discussion}

The purpose of this research is to investigate the effects of Cognitive Therapy Intervention (CTI) towards the resilience of adolescents with behavioral problems. The effects of Cognitive Therapy Intervention (CTI) are reviewed from the differences of subjects' adolescents with behavioral problems resilience mean score. The outcome from the research through ANOVA two way test result for free samples shows that the value of mean score for both treatment group and control group are significantly different. This shows that the Cognitive Therapy Intervention (CTI) has successfully increased the resilience of adolescents with behavioral problem in treatment group compared to the subject in control group.

The results of this research is similar with several other research such as research done by Steen dan Rose (2014), which discovered that group counselling can nourish the education resilience and improve academic achievement Wilkerson et., al (2013); Bruce et., al (2009), social and personal criteria among students. Research by Berger (2014) discovered that group counselling is able to increase motivation and studying and time management skills among students. While research by Ahmad et., al (2014) discovered that intervention using Modul IDEAI method has successfully increase self-regulation aspect, coping skills and students' outcome among the treatment group and control group.

However, the research above is different with this research that gives specific attention to the effects on adolescents with behavioral problem because they need new skills to keep growing and improving along with cognitive changes, social and emotional aspects. This behavioral problem has become a hindrance to the adolescents from achieving development task 
assignment, fulfill social expectation and to feel success along the process of transition to adulthood phase (Karaman, 2013). Along with that, focus towards adolescents with behavioral problems as how it is in this research that strengthen even more the cognitive theory that declare the problematic and aggressive behavior come from the wrong mindset (Beck et al. 1979, Squires $\&$ Caddick, 2012). Therefore, this research intervention is to use cognitive therapy approach because the cognition itself is related with feelings and behavior. Through this CTI, adolescents are encouraged to do reflection on their thinking by considering any relevant proof and eventually give positive outcome towards their feelings and behavior.

This research also discovered that the main effect for free test variables which are pretest, post test and retention test and interaction test effect and group are significant. This means CTI has successfully gives main effect and interaction effect to the increment in resilience among adolescents with behavioral problem. This shows that CTI has not only affect the adolescents with behavioral problems' scores individually but the interaction with the free variable also affect the adolescent in increasing their resiliency.

\section{Implication towards Counselling Practice in School}

CTI Modul is suitable for school counsellor's usage in order to increase resiliency of adolescents with problematic behavior in school mainly in group counselling or group guidance. Firstly, this is because ITK Module itself has gone through a meticulous building process and having high validity and reliability. Throughout the meticulous process of making this CTI module, it has also been checked and assessed by counsellor, language expert, and an expert in counselling course. A pilot test has also been conducted towards the content of this module to check its suitability. CTI Module is specially build based on Cognitive Therapy with a combination of five elements of resiliency and various types of skills and technique to trigger changes in thinking, emotion and behaviour of students. Thus, the resiliency scale instrument and CTI Module can be used as references to school counsellor to identify students with low level of resiliency while using suitable technique to help the students to be stronger in facing their challenges in life.

Research on increases of resiliency also offer new alternative for the administrator, discipline teacher and teachers to nourish the practice of resiliency among students parallel to the desire of Malaysia Education Development Plan 2025 through School Transformation (ST25) movement. Under the field of student outcome in the plan ST25, targeted good character achievement for every student including the aspects of behaving positively which are humanity skills development, decreasing in wrong behavior and increasing of students' attendance to school.

This research also changes the focuses from giving attention from labeling the students as problematic to finding the wrong behavioral sources by looking at the cognitive relation and the effect on emotion and behavior. Hence, the skills to build resiliency that is based on the five components which are Self Reliance, Meanings, Equanimity, Perseverance and Authenticity need to be nurtured so that the students are able to face every resistence, challenges and failure successfully. School authorities are suggested to prepare space so resiliency skills can be absorbed in lesson as a preparation for the students to go through the transition into adulthood. 
INTERNATIONAL JOURNAL OF ACADEMIC RESEARCH IN PROGRESSIVE EDUCATION AND

DEVELOPMENT

Vol. 9, No. 2, 2020, E-ISSN: 2226-6348 @ 2020 HRMARS

Besides that, the important lesson of this resiliency skills lesson need to get as much attention as how academic and co-curriculum achievement are to determine the success in their future.

\section{Future Research}

This research gives more focus on data collecting quantitatively, therefore in the future, it is suggested that the focus is to be more widen on qualitative aspect to give better understanding from the point of view of (a) counsellor's experience in conducting the session and using the module, (b) students' experience after participating in the group and (c) perception of teachers and parents upon seeing the effect of intervention in student's life.

\section{References}

Chang, W. W., Su, H., Wang, J., Wang, C. C., Shan, X. W., \& Han, Q. (2013). Problem behaviours of middle school students in eastern China and its associated factors. Child: Care, Health and Development, 39(5), 660-667. https://doi.org/10.1111/j.1365-2214.2012.01417.x

Cone, J., Golden, J., \& Hall, C. (2009). The effect of short-term cognitive-behavioral group therapy on adolescents with attachment difficulties. Behavioural Development Bulletin, 15(2003), 29-35. Retrieved from

http://content.ebscohost.com. proxy.cityu.edu/ContentServer.asp?T=P\&P=AN\&K=7184776 $1 \& S=R \& D=e h h \& E b s c o C o n t e n t=d G J y M N L$ 80Seprc4yOvqOLCmr02ep7JSsKy4SLKWxWXS\&C ontentCustomer=dGJyMPGrsVGvrrJluePfgeyx44Dt6fIA

Erford, B. T., Paul, L. E., Oncken, C., Kress, V. E., \& Erford, M. R. (2014). Counseling outcomes for youth with oppositional behavior: A meta-analysis. Journal of Counseling \& Development, 92(1), 13-24. https://doi.org/10.1002/j.1556-6676.2014.00125.x

Hogendoorn, S. M., Prins, P. J. M., Garst, H., Hartman, C. A., \& Haan, E. De. (2014). Mediators of Cognitive Behavioral Therapy for Anxiety-Disordered Children and Adolescents : Cognition , Perceived Control , and Coping, 43(3), 486-500.

https://doi.org/10.1080/15374416.2013.807736

Karahan, T. F., Yalçin, B. M., \& Erbaş, M. M. (2015). The Beliefs, Attitudes and Views of University Students about Anger and the Effects of Cognitive Behavioral Therapy-Oriented Anger Control and Anxiety Management Programs on Their Anger Management Skill Levels. Educational Sciences: Theory \& Practice, 14(6), 2071-2082.

https://doi.org/10.12738/estp.2014.6.2314

Loh, J. M. I., Schutte, N. S., \& Thorsteinsson, E. B. (2014). Be Happy: The Role of Resilience Between Characteristic Affect and Symptoms of Depression, 1125-1138. https://doi.org/10.1007/s10902-013-9467-2

Milkman, H. B., \& Wanberg, K. W. (2012). Adolescent Development and Pathways to Problem Behavior. Criminal Conduct and Substance Abuse Treatment for Adolescents: Pathways to Self-Discovery and Change, 21-54.

Noltemeyer, A. L., Ward, R. M., \& Mcloughlin, C. (2015). Relationship between school suspension and student outcomes: A meta-analysis. School Psychology Review, 44(2), 224-240.

Padesky, C. A., \& Mooney, K. A. (2012). Strengths-Based Cognitive-Behavioural Therapy : A FourStep Model to Build Resilience, 290(May), 283-290. https://doi.org/10.1002/cpp.1795

Sun, R. C. F., \& Shek, D. T. L. (2013). Longitudinal Influences of Positive Youth Development and 
INTERNATIONAL JOURNAL OF ACADEMIC RESEARCH IN PROGRESSIVE EDUCATION AND DEVELOPMENT

Vol. 9, No. 2, 2020, E-ISSN: 2226-6348 @ 2020 HRMARS

Life Satisfaction on Problem Behaviour among Adolescents in Hong Kong. Social Indicators Research, 114(3), 1171-1197. https://doi.org/10.1007/s11205-012-0196-4

Wang, J.-N., Liu, L., \& Wang, L. (2014). Prevalence and associated factors of emotional and behavioural problems in Chinese school adolescents: a cross-sectional survey. Child: Care, Health and Development, 40(3), 319-326. https://doi.org/10.1111/cch.12101 